\title{
Um Software Móvel Acadêmico em uma Instituição de Ensino Superior
}

\author{
Fabio Fonseca Barbosa Gomes ${ }^{1}$ \\ https://orcid.org/0000-0001-5113-9553 \\ Marcelo Santos Silva ${ }^{2}$ \\ https://orcid.org/0000-0003-4140-8179 \\ Diego Passos Costa \\ https://orcid.org/0000-0001-7588-4160
}

\section{RESUMO}

A tecnologia da informação e comunicação evolui e se populariza, cada vez mais, com o aumento de processamento e miniaturização dos computadores. Além do surgimento de novas formas de comunicação sem fio. Isto permite que a sociedade consiga aperfeiçoar uma série de procedimentos nas organizações. No caso das instituições de ensino superior, uma solução computacional para a melhoria de diversos processos da instituição é a utilização dos sistemas Web. A burocracia e a falta de comunicação rápida entre os setores tomam muito tempo para o encontro de resoluções, além de gerarem filas de espera e desgastes como aborrecimentos. Para diminuir os possíveis problemas de atraso, este artigo propõe um sistema Web que tem a capacidade de comunicar com os setores responsáveis por cada demanda e uma pesquisa de campo entre alunos. Foi realizada uma pesquisa exploratória juntamente com os alunos de uma instituição de ensino superior e os resultados se mostraram promissores. A pesquisa realizada neste artigo, concluiu que um sistema Web instalado em uma instituição de ensino superior é bastante eficaz e fácil de aprender por parte dos usuários, consequentemente, reduzindo o tempo de espera para a solução de algum problema administrativo ou acadêmico na instituição de ensino superior.

Palavras-Chave: Aplicativo Móvel, Sistema Educacional, Tecnologia da Informação.

\section{Un Software Móvil Académico en una Institución de Educación Superior \\ RESUMEN}

La tecnología de la información y la comunicación evoluciona y es cada vez más popular con el aumento del procesamiento y la miniaturización de las computadoras. Además de la aparición de nuevas formas de comunicación inalámbrica. Esto permite a la sociedad ser capaz de mejorar una serie de procedimientos en las organizaciones. En el caso de las Instituciones de Educación Superior, una solución computacional para la mejora de diversos procesos de la institución es el uso de sistemas web. La burocracia y la falta de comunicación rápida entre sectores tardan mucho tiempo en cumplir las resoluciones, así como para generar colas y desgaste como molestias. Para reducir posibles problemas de retraso, este artículo propone un sistema Web que tiene la capacidad de comunicarse con los sectores responsables de cada demanda y una investigación de campo entre los estudiantes. Se llevó a cabo una investigación exploratoria junto con estudiantes de una Institución de Educación Superior y los resultados resultaron prometedores. La investigación llevada a cabo en este artículo concluyó que un sistema Web instalado en una Institución de Educación Superior es bastante eficaz y fácil de aprender de los usuarios, además de que puede reducir el tiempo de espera para la solución de algún problema administrativa o académico de la Institución de Educación Superior.

Palabras-Clave: Aplicativo Móvil, Sistema Educacional, Tecnología de la Información.

\section{A Mobile Academic Software in a Higher Education Institution}

\section{ABSTRACT}

Information and communication technology is evolving and becoming increasingly popular with the increasing processing and miniaturization of computers. In addition to the emergence of new forms of wireless communication. This allows society to be able to improve a range of procedures in organizations. In the case of higher education

\footnotetext{
${ }^{1}$ Centro Universitário Regional do Brasil, Centro Universitário Dom Pedro II, Fundação Visconde de Cairu, Instituto Federal de Educação, Ciência e Tecnologia da Bahia, Brasil. Email: fabiofbg@gmail.com

${ }^{2}$ Eurodata Interativa, Brasil. Email: falecom.marcelo@live.com

${ }^{3}$ Faculdade Maurício de Nassau, Brasil. Email: diegopassoscosta@gmail.com
} 
institutions, a computational solution for the improvement of various processes of the institution is the use of Web systems. Bureaucracy and lack of rapid communication between sectors take a long time to reach resolutions and generate queues and wear as annoyances. To alleviate possible delays, this article proposes a Web system that has the ability to communicate with the sectors responsible for each demand and a field survey among students. An exploratory research was conducted with the students of a higher education institution and the results were promising. The research conducted in this article concluded that a Web system installed in a higher education institution is very effective and easy for users to learn, thus reducing the waiting time for solving any administrative or academic problem in the superior educational institution.

Keywords: Mobile Application, Educational System, Information Technology.

\section{Introdução}

Atualmente, as instituições de ensino superior possuem diversos procedimentos burocráticos que, muitas vezes, são feitos de forma manual, como o caso de procedimentos de reclamações, rematrícula, grade de semestre e diversas situações. Para um aluno resolver algum problema, ele tem que ir ao departamento específico, efetuar uma série de procedimentos burocráticos que demandam muito tempo para serem solicitados e confeccionados.

Por muitas vezes, isso pode frustrar os alunos sobre as suas expectativas em relação a universidade. Alguns até tem seus sistemas de auxílio ao aluno e professores, por exemplo: um aluno veterano se matricula na internet, recebe notícias sobre alguma palestra ofertada pela mesma através da estrutura fornecida, tem informações de seus núcleos de prática com mais facilidade, o mesmo caso é dos docentes, que é capaz de solucionar através de um software acadêmico.

Mesmo com essas soluções demonstradas, existe uma grande demora para resolver as questões acadêmicas. Desta forma, como maneira de solucionar estas disfunções, a proposta é apresentar um programa online acadêmico em uma instituição de nível superior, no qual o aluno não perca tempo se locomovendo. Uma das vantagens desta solução é a capacidade de reduzir horas desperdiçadas para conseguir solicitar um serviço que poderia ser solucionado no navegador $W e b$ ou aplicativo, como verificar a grade dos semestres, solucionar sala de aulas que esteja com equipamentos defeituosos, saber corretamente o caminho para chegar em determinadas salas, dias de palestra que são ofertados e outros meios que possa ajudar o usuário usufruir.

O sistema sugerido oferecerá um serviço de auxílio, semelhante a uma agenda, com um diferencial: ao entrar no site, aparecerá um questionamento perguntado se deseja colocá-lo na página inicial do celular ou entre os aplicativos, mas para isso acontecer, o mesmo deve possuir instalado em seu dispositivo computacional o navegador Firefox, Opera on Google Chrome.

Segundo Lakatos e Marconi (2003), os trabalhos científicos são classificados através de metas a serem alcançadas e procedimentos técnicos. Sobre as metas, o trabalho utiliza os tipos de pesquisa: exploratória; explicativa e descritiva. Em relação aos procedimentos técnicos, este artigo utiliza uma pesquisa bibliográfica e exploratória, com a utilização de um experimento feito com 50 alunos de uma instituição de ensino superior que passam por este problema, os usuários foram selecionados de forma aleatória na instituição para fazer o experimento.

Para o experimento ser realizado, foi necessário a seleção de alunos de diversos cursos de nível superior da instituição de ensino, não só alunos de informática. Foram escolhidos alunos que tinham conhecimento em manejo de dispositivos móveis, mas também alunos que não tem esse conhecimento avançado, como forma de analisar quais seriam as possíveis dificuldades que eles iriam ter utilizando a solução proposta. Os alunos utilizaram a ferramenta percorrendo todas as suas funcionalidades, depois responderam a um questionário, como será detalhado mais adiante, neste artigo.

\section{Conceitos de Sistemas $W e b$}

O sistema Web é uma estrutura de software necessário para ter um cadastro e realizar o acesso [Garcia e Abilio, 2017]. Com essa permissão, ele poderá se conectar com a página da rede. A sua diferença é que os sites comuns são formas mais informativas e estatísticas, como blogs, notícias e tutorias, pois não possui ferramenta de gerenciamento ao site. 
Segundo Winckler e Pimenta (2002, p. 10), "A arquitetura é basicamente cliente/servidor instalado sobre uma rede de computadores heterogênea". Então, o projeto criado será interpretado de forma interativa através dos navegadores ao cliente. Sua vantagem no desenvolvimento é não precisar investir em infraestrutura, já que existes provedores (servidores), o acesso pode ser feito de qualquer dispositivo computacional conectado a $W e b$.

Além disso, a segurança do servidor $W e b$ pode ser implementada através de algumas restrições, como o exemplo da utilização da restrição através de usuário e senha. Neste trabalho, será utilizado o servidor Web Apache, visto que ele é "projetado para trabalhar com uma ampla variedade de plataformas e ambientes. Isto é possível devido a sua implementação modular." [Semprebom et al., 2006].

\section{Características do Sistema $\mathbf{W e b}$}

O comportamento do sistema Web é dinâmico. A sua ligação com a conexão via servidor através da rede é um caminho para que duas ou mais máquinas tenham comunicação. De acordo com Kurose e Ross (2010), o HTTP (Protocolo de Hiper Texto - Hypertext Transfer Protocol) é o idioma que os navegadores e os servidores se comunicam. $\mathrm{Na}$ base cliente/servidor, o navegador do cliente irá solicitar uma requisição, enquanto, o servidor envia em resposta a página $W e b$ de volta. Para Kurose e Ross (2010), o HTTP é um protocolo sem estado, um exemplo disso é quando o cliente solicita uma nova requisição e, ao mudar a página, o servidor não grava a requisição anterior. Esta requisição é uma comunicação do cliente com o servidor através do servidor N (Domain Name Server - Servidor de Domínio de Nomes), que tem a função de "converter" os sítios da $W e b$ em seus endereços IP correspondentes, como pode ser visualizado no passo 1 da figura 1.

Após, é feita a comunicação com o servidor Web diretamente pelo endereço IP do mesmo, que responde ao cliente, atendendo a solicitação. Além disso, no passo 3 da figura 1 é utilizado o Protocolo de Controle de Transmissão (TCP) - Transmission Control Protocol, em que as mensagens da requisição são quebradas em segmentos e enviadas através da rede no TCP, e suas propriedades é confiável, garantido que a aplicação está pronta para receber os dados, ele confirma os dados completo e entrega na ordem que foram enviados na sua sequência.

Desta forma, no passo 3 da figura 1, pode-se ver a utilização de um comando get, que é a solicitação do cliente para o servidor solicitando acesso a um sítio específico. Após, é possível ver a resposta so servidor $W e b$ através da utilização da confirmação do servidor, juntamente com as informações do sítio solicitado. Finalmente, no passo 4 da figura 1, a solicitação do cliente é atendida e a página é carregada. 
Figura 1. Demonstração de uma conexão TCP

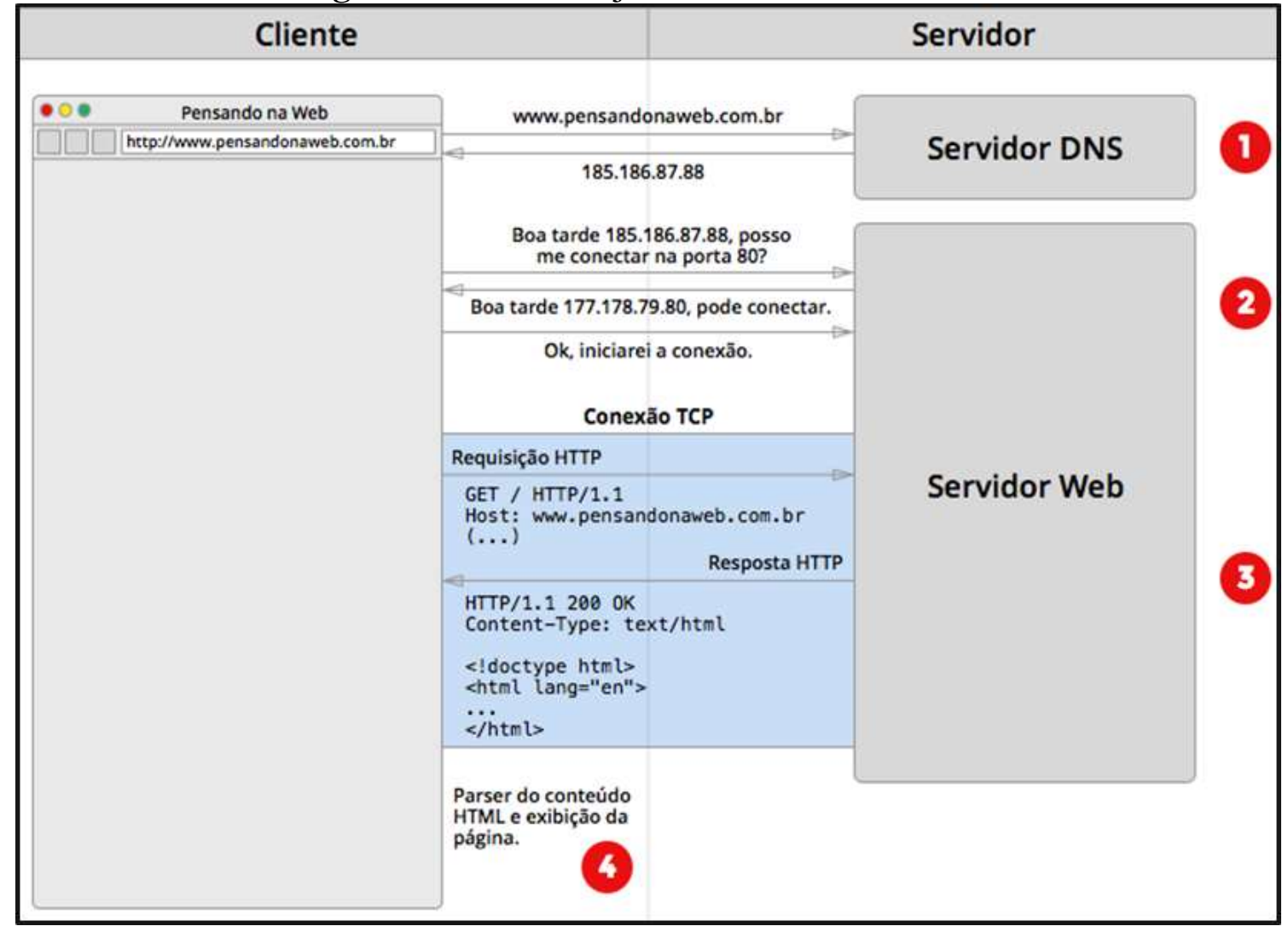

Fonte: Santos (2014).

\section{Trabalhos Correlatos de Sistemas acadêmicos}

Os autores Ribeiro et al. (2011), apresentam o projeto LEW (Figura 2), que demostra sua execução com uma interface amigável, fornecendo um ambiente para gerenciamento de informações. Ele foi criado com o intuito de ajudar aos alunos, pesquisadores e professores a compartilhar informações, atividades da instituição, além de alguns softwares adicionais feitos por eles. "O LEW executa em um portal $W e b$ com uma interface amigável ao usuário, que fornece um ambiente para gerenciamento de informações relacionadas às atividades de ensino, pesquisa e extensão vinculadas à Universidade Federal de Sergipe”. 
Figura 2. Página Inicial do LEW

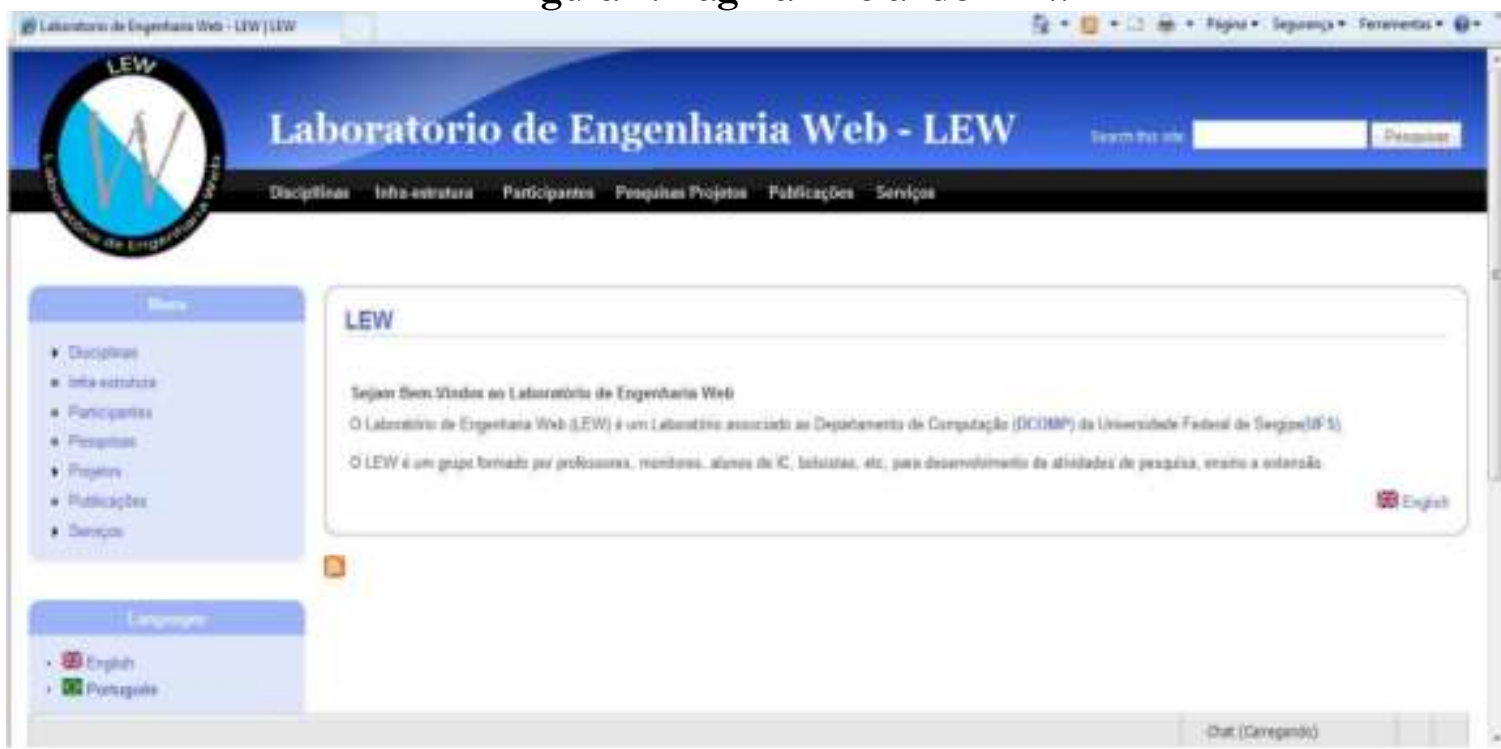

Fonte: Ribeiro et al. 2011).

No entanto, o desenvolvimento ficou muito preso em interface de telas maiores. No caso do smartphone, a resolução irá ficar desproporcional, forçando o aumenta e diminuição da função de zoom do aparelho. Costa et al. (2010) apresentaram uma solução flexível, que permite reduzir custos de transição, orientado a serviço que dá suporte ao sistema gestão de bases de dados. Sua criação foi voltada a diminuir o tempo na gestão da universidade, agilizando serviços e trazendo eficiência na unidade, conforme pode ser vista na figura 3.

Figura 3. Página Inicial do LEW

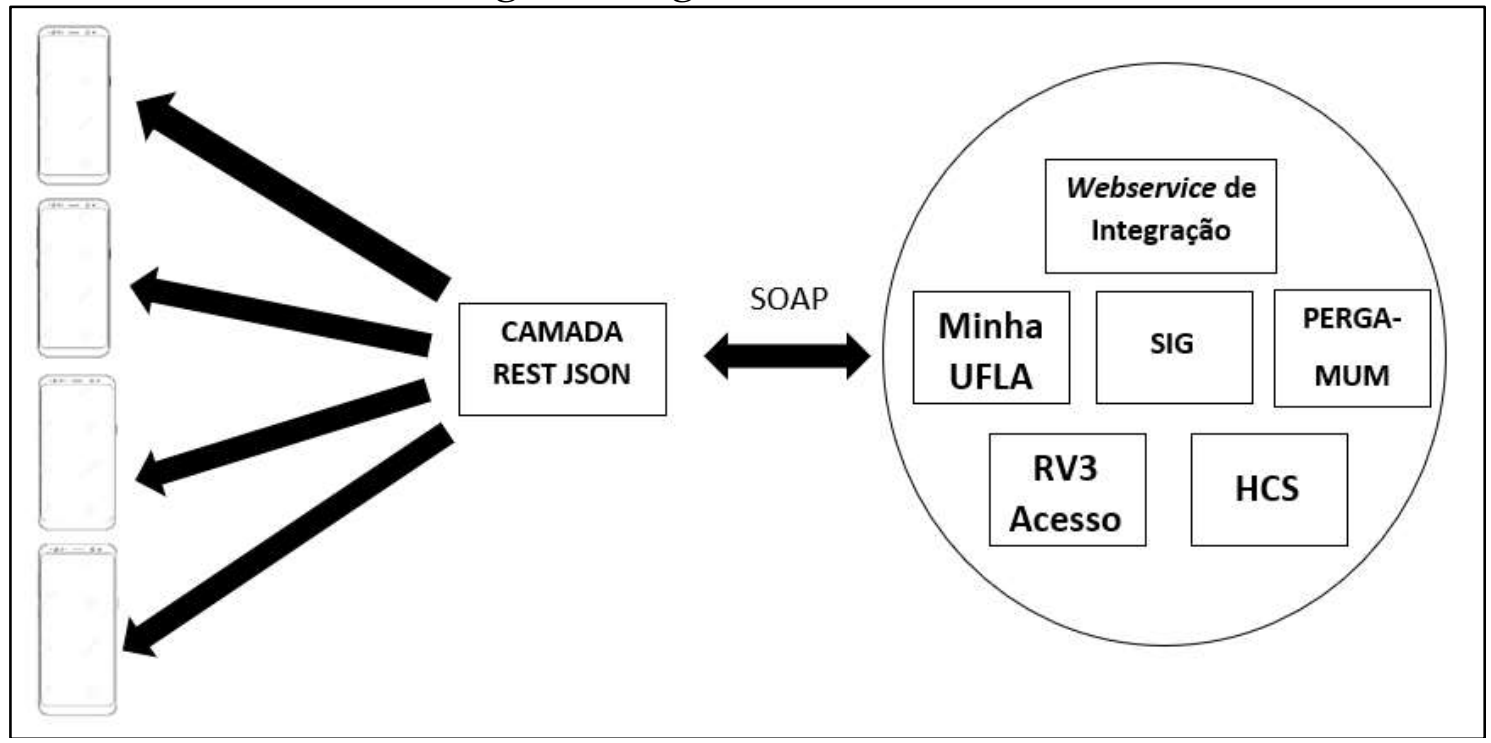

Fonte: Costa et al. (2010)

A Figura 3 apresenta a arquitetura da solução proposta por Costa et al. (2010), nela os smartphones com a aplicação móvel utilizam o JSON (JavaScript Object Notation - Objeto de Notação JavaScript) se conectam com uma camada, chamada de REST-JSON (Representational State Transfer Transferência Representacional de Estado). Essa, por sua vez, se comunica com SOAP (Simple Object Access Protocol - Protocolo Simples de Acesso a Objetos) com a Webservice de integração. Verifica-se que, de acordo com esse trabalho apresentam flexibilidade e eficiência na utilização. 
Analisando na situação dos discentes, ele está muito voltado para a universidade, facilitou a reduzir tempo, porém não apresentou táticas de o aluno realizar isso online sem precisar ir ao setor. Essa mudança pode trazer uma redução mais relevante para ambos.

Outro semelhante aos citados anteriormente foi feito por Freire et al (2005), a implementação das funcionalidades que foi criado nesse projeto mostra funções não encontradas normalmente em projetos $W e b$ institucional, suas características gerais a serem utilizados pelas instituições contribui à melhoria da qualidade de seus cursos, facilitar as tarefas que devem ser desenvolvidas pelos professores e também no desenvolvimento dos planos de ensino.

A solução de Freire et al. (2005), é composta por um computador sendo conectado através de uma rede $W i$-Fi ou de uma rede de Celular com o sistema $W e b$ que está sendo executado diretamente pelo servidor. Este sistema Web possui um SGBD (Sistema Gerenciador de Bancos de Dados) incorporado a ele. Apesar de bons resultados, este trabalho não apresentou novos planejamentos, visto que focou na verificação. Como sugestão para este projeto, poderiam existir outras formas de inclusão para elaborar métodos de união dos clientes.

Além dos trabalhos anteriores, o projeto criado por da Silva et al. (2011) tem como principal objetivo a criação de um software para uma escola de música utilizando um servidor web. No caso do trabalho de da Silva et al. (2011), o servidor Web foi implementado através da linguagem Java com a interface de desenvolvimento NetBeans. O sistema mostrou-se eficiente e atendeu as expectativas da escola de música.

Os autores António e Gouveia (2014), criaram um sistema utilizando servidor Web para fazer o acolhimento de alunos novatos em uma instituição de ensino superior em Angola. Os autores citam que: "No sentido de personalizar as necessidades de um aluno do $1^{\circ}$ ano e facilitar a sua interacção com a universidade, aproveitando os seus colegas de outros anos e o suporte de tecnologia, é estudado um sistema de acolhimento que possa satisfazer as necessidades no contacto com a Universidade".

Em relação aos resultados deste projeto, os autores informaram que o sistema resolveu boa parte dos problemas da universidade, resultando em facilidade na integração dos alunos novatos com a instituição de ensino. Na figura 4 é possível visualizar a interface de entrada do sistema criado por António e Gouveia, a intenção é facilitar a integração dos novos alunos com a instituição de ensino angolana. 
Figura 4. Tela de Acesso ao Sistema Acadêmico

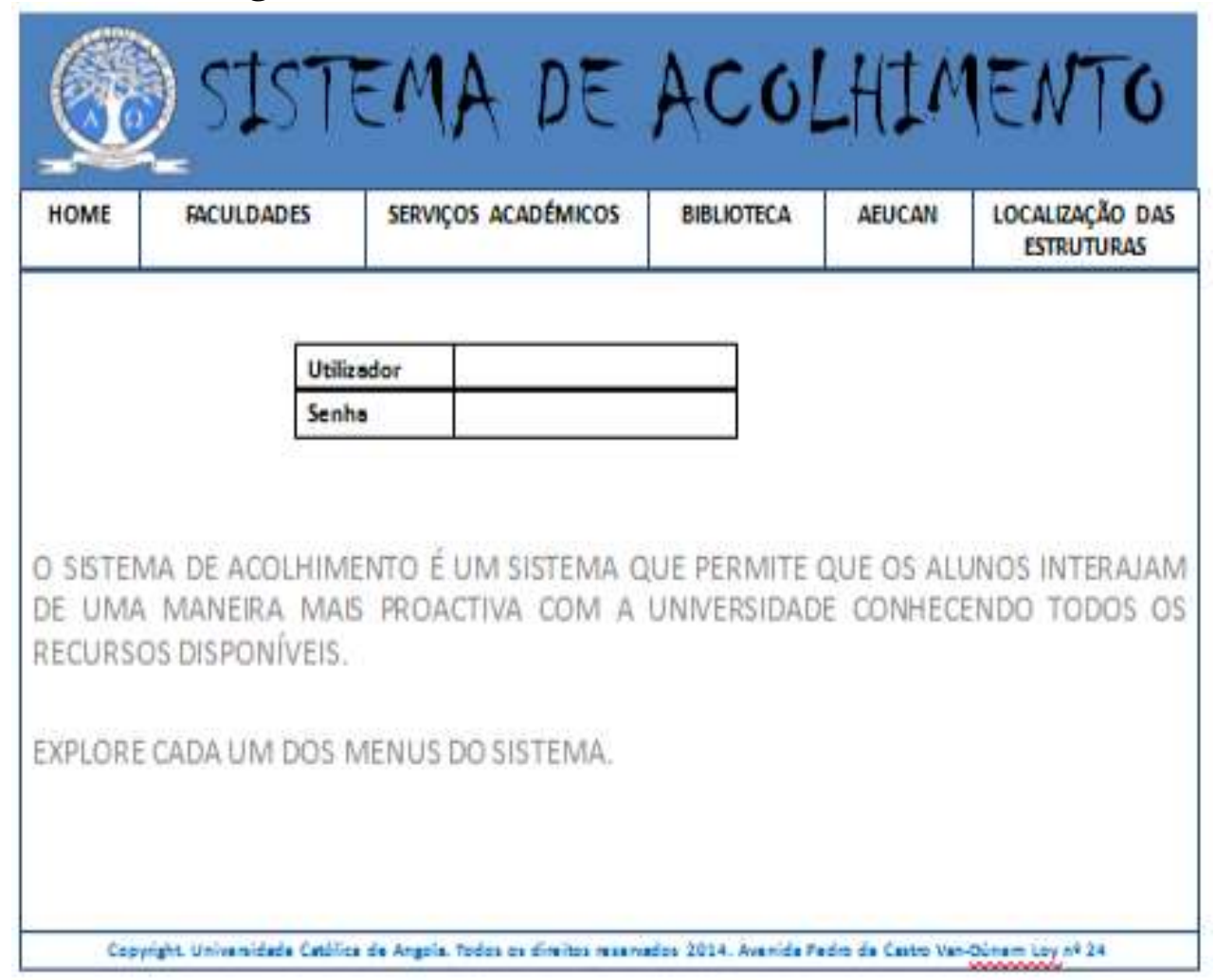

Fonte: Costa et al. (2010)

Desta maneira, os trabalhos apresentados nesta seção serviram como fator motivador para a criação de um sistema destinado a integrar informação, novidades, acessibilidade, e redução de tempo ao usuário conectado nesse serviço.

\section{O Software Acadêmico FaceAcad}

Os trabalhos pesquisados na seção anterior serviram de inspiração para a solução proposta, como forma de mitigar os problemas de demora para atendimento aos alunos e, também, para otimizar o atendimento aos mesmos de forma confortável e com qualidade, foi desenvolvida a solução proposta neste trabalho, que é o Software Acadêmico FaceAcad (Figura 5).

Figura 5. Logomarca do FaceAcad

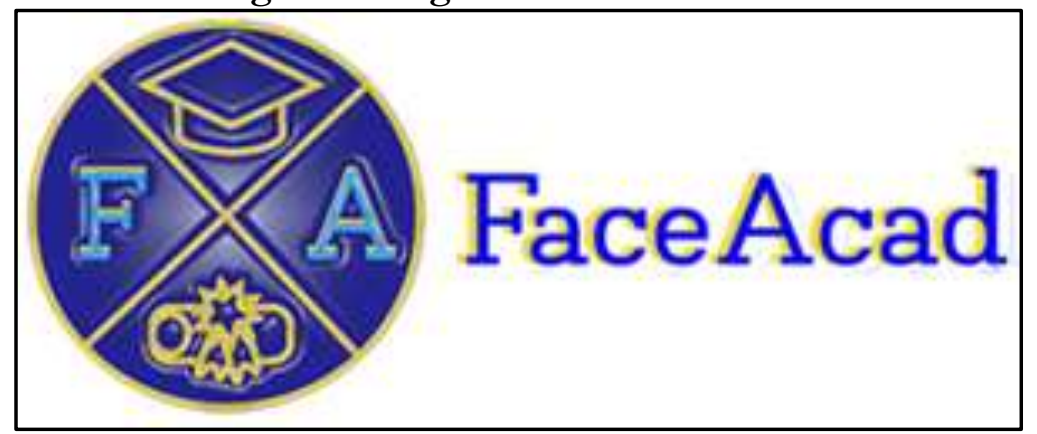

Fonte: Autoria própria.

Para o desenvolvimento desta solução, foram utilizadas as seguintes ferramentas como instrumento de criação do projeto: 
- A linguagem de programação PHP pelo fato de ter bastante interação com o mundo Web [Niederauer, 2011], e ser possível realizar mudanças caso seja necessário fazer alguma alteração de acordo com a necessidade dos usuários.

- O template (modelo) das páginas usado como interface do conteúdo de design do sistema [Spurlock, 2013], foi da Start Bootstrap, pois a resolução se adequada de acordo com o dispositivo a ser utilizado,

- Banco de dados SGBD relacional que utiliza a linguagem padrão SQL (Structured Query Language) [Niederauer, 2005], utilizada foi a MySql Workbench para armazenamento da informação.

- O servidor $W e b$ funciona através da utilização do Apache, pelo fato de ser um software popular e de fácil utilização.

\section{Diagrama de caso de uso}

O diagrama de caso de uso resume relações entre atores e sistema [Larman, 2002]. O objetivo é mostrar a interação com o sistema. Ele lida apenas com os requisitos funcionais. A figura 6 ilustra o diagrama de casos de uso referente a proposta. Por meio da análise é possível coletar os dados para criar soluções de acordo com a necessidade do usuário.

Figura 6. Caso de uso no sistema $\mathrm{Web}$

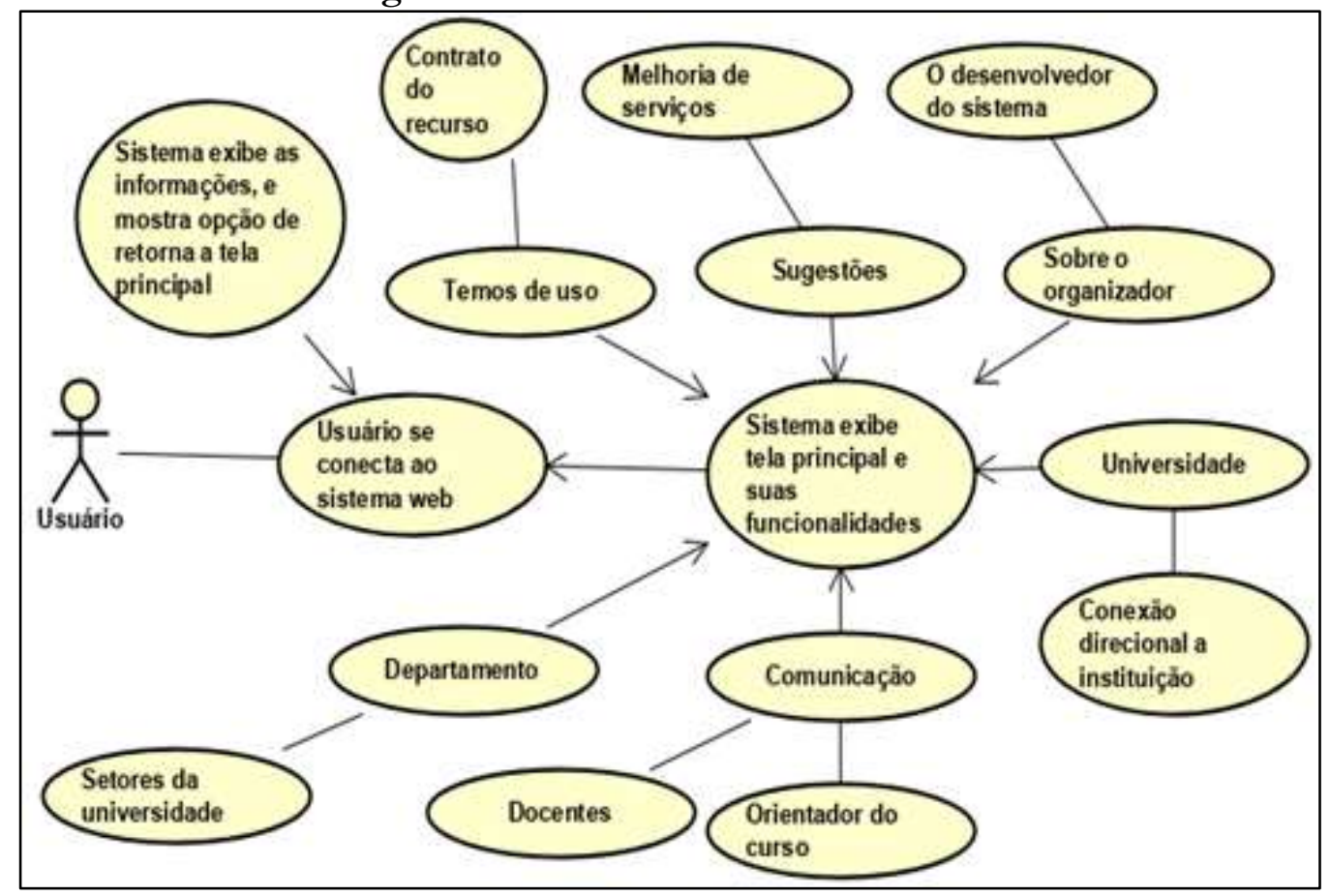

Fonte: Autoria própria.

De acordo com a estrutura projetada na figura 6, quando o aluno entrar no sistema, ele irá receber uma série de opções para sua escolha. Essas escolhas permitem ao indivíduo o poder de captar informações com mais facilidade em relação aos processos existentes dentro da instituição. Um exemplo disso seria o caso do aluno querer sair da aplicação para ir direto para o site da instituição, lá terá a função direta com a página da mesma.

Com essa visão da imagem percebe-se que o aluno terá uma base de dados para procurar suas soluções. Desta forma, vê-se que o aluno ele terá a conexão com o sistema para busca de dados, de acordo com sua necessidade acadêmica. 


\section{Modelo Conceitual MER}

O MER (Modelo de Entidade Relacional) representar a semântica associado aos dados. [Date, 2004], com esse conjunto de elementos você aprendera como funciona o sistema. Através das informações colhidas que teremos a base das regras e como será representado em passos.

- Os usuários se conectam no sistema Web.

- Somente usuários da rede da instituição podem realizar cadastramento. Devem ser armazenadas as seguintes informações: nome, sobrenome, e-mail institucional, senha e código da instituição.

- O sistema exibe uma variedade de opções para solucionar o problema apresentado, por exemplo: se o usuário, que já estar conectado, solicitar o departamento de TI, será mostrado na interface o nome, e-mail e telefone.

- O setor irá responder por ligação ou e-mail do usuário.

- Poderá ter vários serviços da instituição no sistema $W e b$, e cada ramo deverá possuir um código único.

\section{Diagrama entidade-relacionamento DER}

Figura 7. Diagrama de conexão ao sistema $W e b$

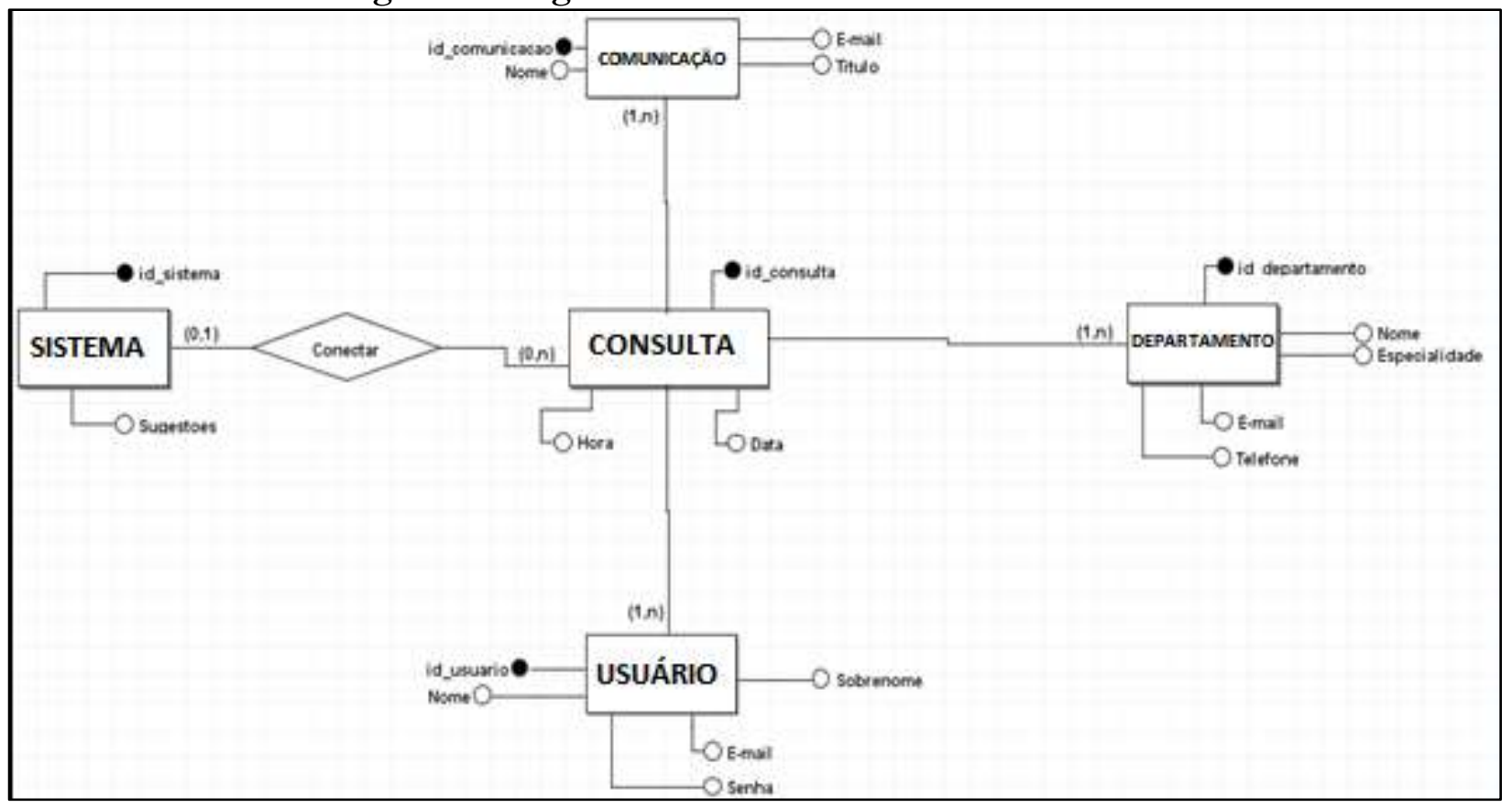

Fonte: Autoria própria.

Para Date (2004), o diagrama entidade relacionamento (DER) é a representação gráfica do MER e principal ferramenta para a compreensão do modelo conceitual. A representação da figura destacar a conexão do usuário ao sistema sendo que o programa tem departamento, cada entidade no retângulo possui seus tributos, que foram apresentados (nome, e-mail, telefone) na sessão 4.2 no MER, que pode ser visto na figura 8 . 
Figura 8. Modelo de Entidade e Relacionamento do sistema Web

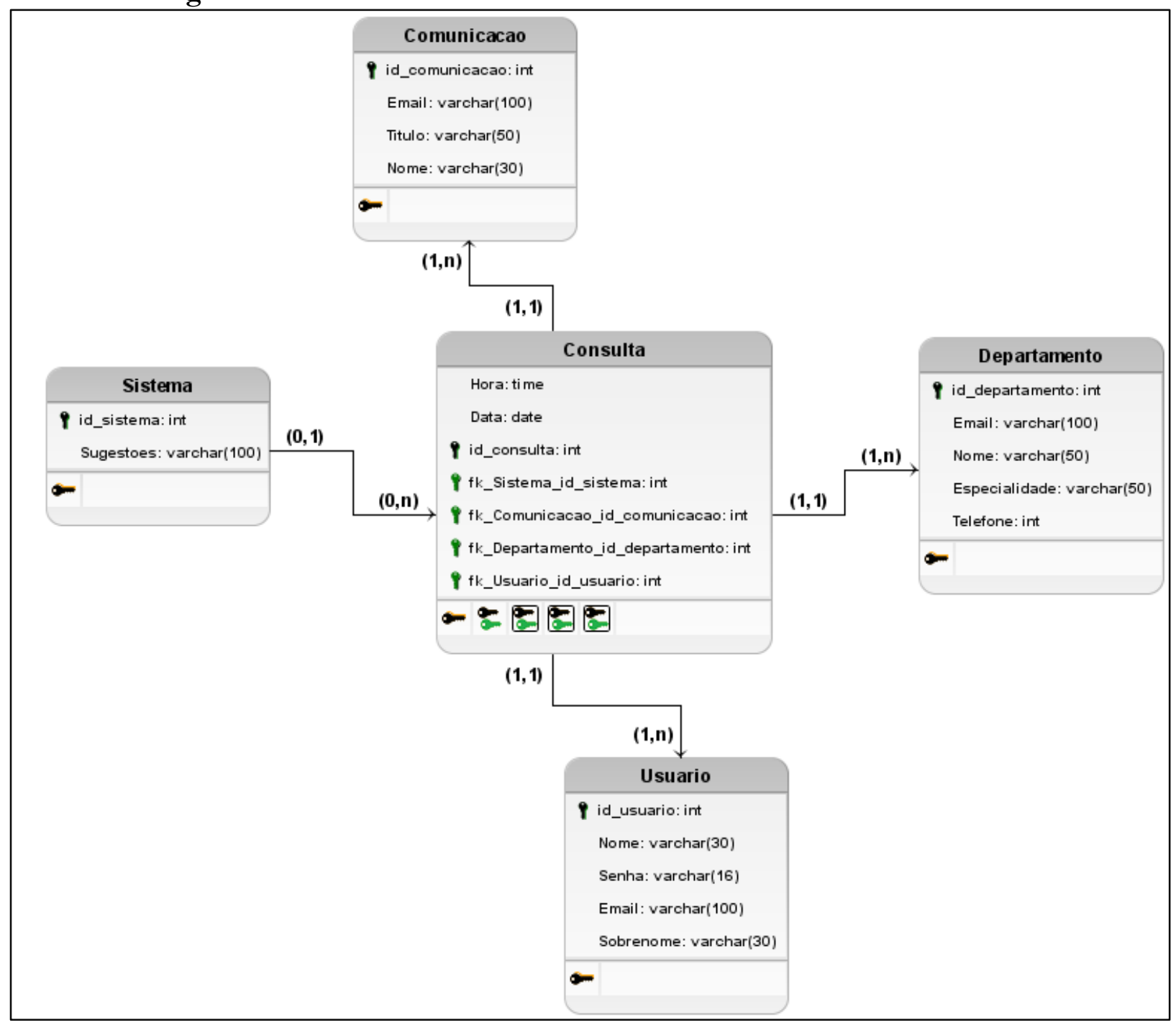

Fonte: Autoria própria.

\section{Descrição do sistema proposto}

Nas seções anteriores identificou-se os requisitos funcionais no diagrama de caso de uso, olhamos o percurso através do conceito do MER e a conexão do usuário através do DER. O programa apresenta uma interface com resolução adequada para cada dispositivos computacionais que o usuário for usar, e que fornece um ambiente para gerenciamento de informações relacionados aos departamentos. 
Sapientiae | $305 \mid$

Figura 9. Interface de acesso ao sistema

$\triangle \Delta B \ldots$

K. $8.4100 \%$ : $08: 19$

() (1) 192.168.0.20/academic (2) :

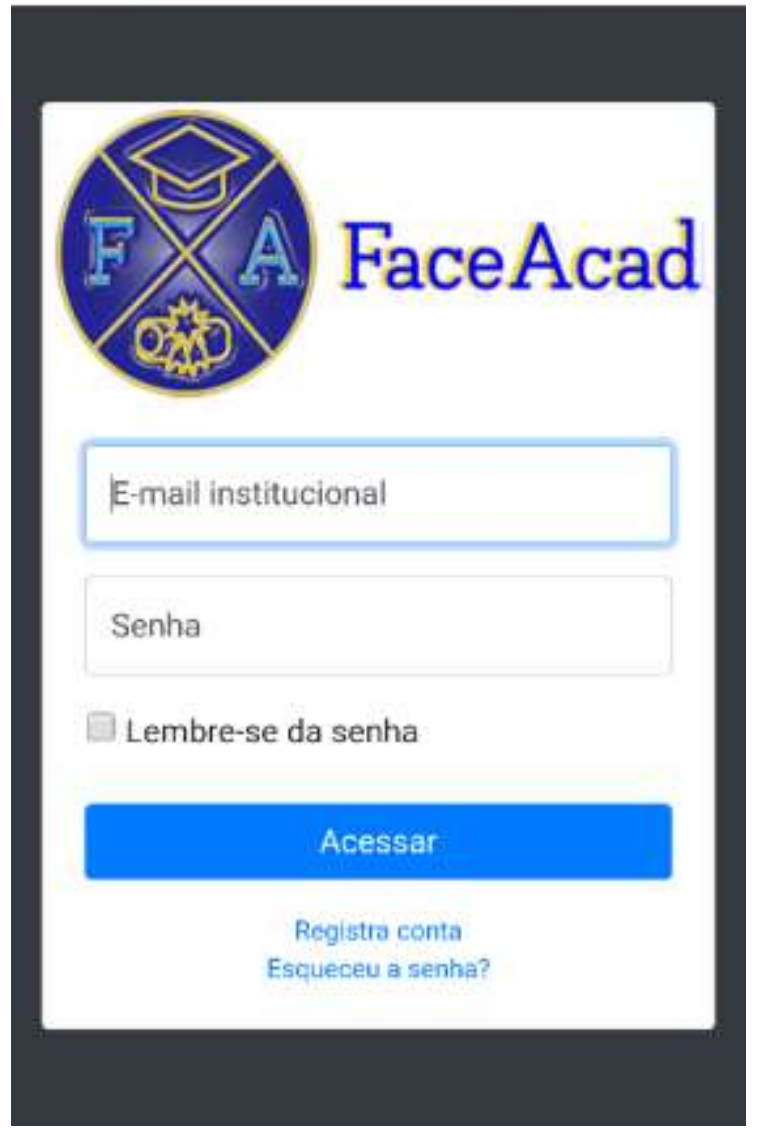

Fonte: Autoria própria.

$\mathrm{Na}$ interface para navegação, temos a tela de acesso que solicita e-mail institucional e senha, ilustrado na figura 9. Ele faz o barramento para o acesso restrito ao programa $W e b$, lembrado que, para fazer o cadastramento deve possuir o e-mail institucional, pois ele é de importância para realização de problemas. Isso é uma forma de comunicação, com alunos que não conhece muito sua função, e vão aprender formas de usa com auxílio do software.

A tela vista na figura 10 funciona para a identificação dos usuários cadastrados, pois ela realiza o acesso dos usuários da instituição. Caso ele deseje lembrar a senha para o acesso rápido, basta marcar a caixa (Lembre-se da senha) ou se esqueceu, existe a forma de recuperação da senha através do e-mail. 
Sapientiae | 306 |

Figura 10. Interface cadastro do sistema

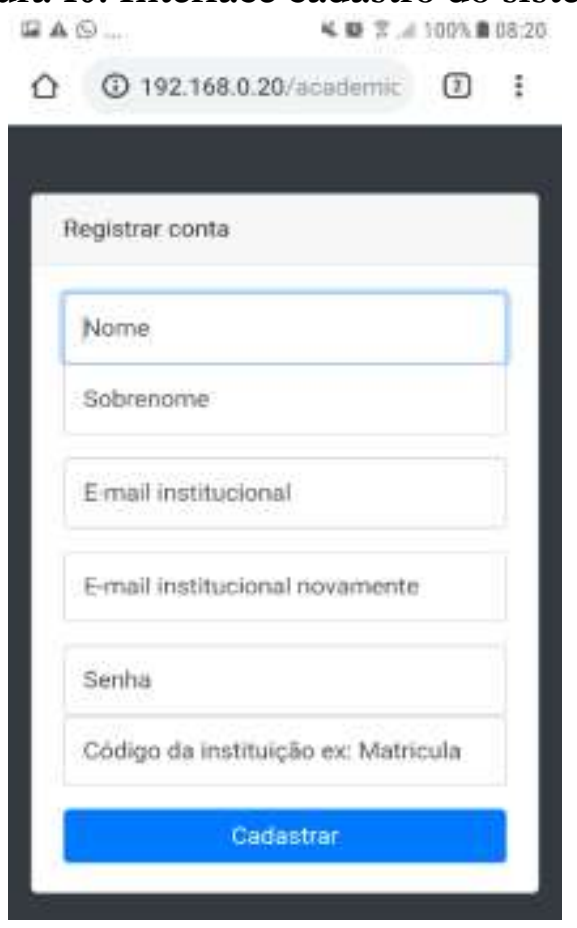

Fonte: Autoria própria.

A tela da figura 10 apresenta um formulário em que o usuário deve digitar apenas os dados básicos para identificação que são: nome, sobrenome, e-mail institucional, senha, código da instituição.

Tudo de acordo com o uso do usuário. Já as figuras 11 e 12 apresentam uma tela de boas-vindas para as páginas de acesso rápido do sistema, em que o usuário verifica a logomarca, o menu a direta (Usuário) é para caso queira sair ou verificar suas informações, e o da esquerda é a tela de atalhos.

Figura 11. Interface da página principal

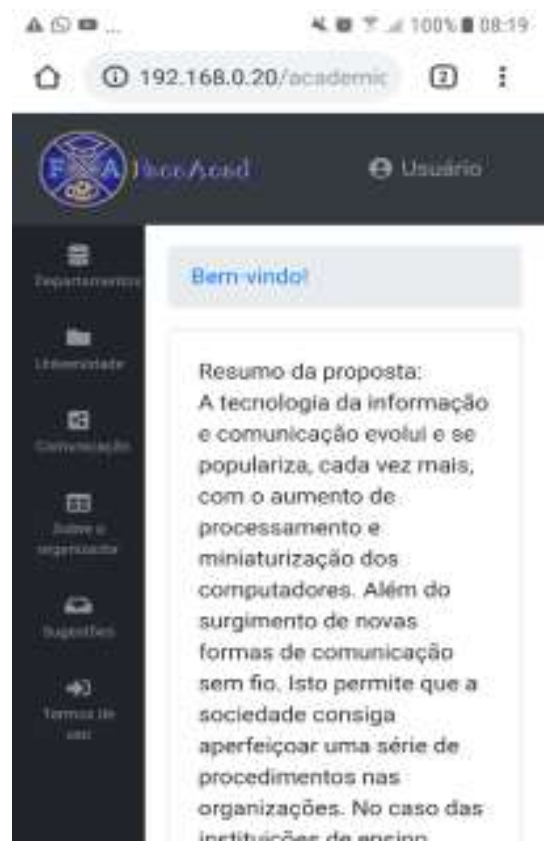

Fonte: Autoria própria. 


\section{Figura 12. Interface da página principal}

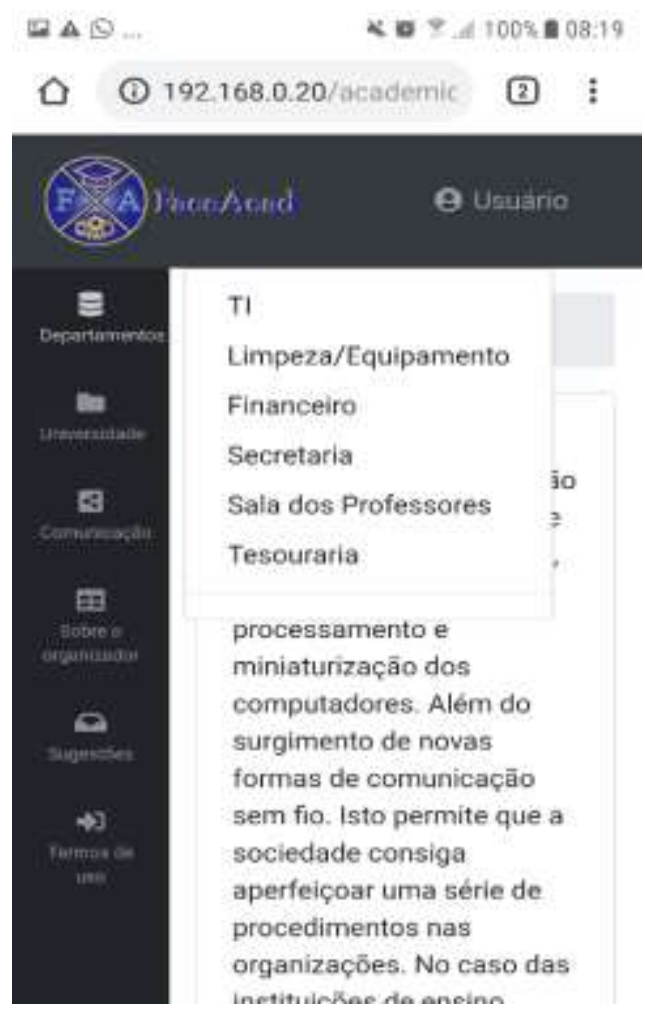

Fonte: Autoria própria.

\section{PESQUISA DE CAMPO}

Foi feita uma pesquisa de campo entre alunos (com a faixa de idade entre 18 e 50 anos) em uma instituição de ensino superior localizada na cidade de Salvador, estado da Bahia, Brasil, no período 2018-2. O objetivo desta exploração foi saber se o aluno tem facilidade de resolver os procedimentos burocráticos da faculdade de forma mais eficiente. Ele também deseja que a instituição tivesse mais opções para solucionar estes problemas, como exemplo um sistema Web. Para a análise quantitativa, foram levantadas as seguintes perguntas vistas na tabela 1:

\section{Tabela 1. Questões utilizadas no experimento}

\begin{tabular}{|c|l|}
\hline Número & \multicolumn{1}{|c|}{ Pergunta } \\
\hline 1 & $\begin{array}{l}\text { Você consegue, com facilidade, resolver problemas burocráticos na } \\
\text { instituição? }\end{array}$ \\
\hline 2 & $\begin{array}{l}\text { Se existisse uma solução Web que o ajudasse a resolver esses problemas, } \\
\text { você usaria? }\end{array}$ \\
\hline 3 & Gostaria que a instituição tenha mais opões Web e app? \\
\hline 4 & $\begin{array}{l}\text { Você sabia que é possível renovar livro um livro na biblioteca virtual da } \\
\text { instituição, pelo Portal do Aluno? }\end{array}$ \\
\hline
\end{tabular}

\section{Fonte: Autoria Própria}

Em relação as respostas das perguntas feitas na tabela 1 foi utiliza uma escala simples de Sim para respostas afirmativas ou Não para as respostas negativadas. O teste com o público foi feito da 
seguinte forma: primeiramente o sistema era explicado para ele e depois o indivíduo fazia o teste utilizando todas as telas do sistema e, também, utilizando todos os recursos disponíveis para ele. Após esta etapa, os dados eram coletados e catalogados e, por fim, após a apuração das informações coletadas com os alunos da instituição de ensino superior. Através desses dados foram criados gráficos com os resultados, que são apresentados nas figuras 13 e 14 de um total de 50 alunos, sendo 25 alunos do turno matutino e 25 do turno noturno, os alunos foram escolhidos de forma aleatória. A quantidade de alunos foi definida como critério mínimo para fazer o experimento e, também, era o limite disponível na sala de aula, naquele momento.

Além disso, foram escolhidos alunos que tinham conhecimento em manejo de dispositivos móveis e aqueles que não tem esse conhecimento avançado. A principal intenção foi realizar uma análise sobre quais seriam as possíveis dificuldades que eles iriam ter utilizando a solução proposta. Eles utilizaram todas as funcionalidades disponíveis no programa. Após, eles responderam a um questionário, conforme as perguntas apresentadas na tabela 1.

Figura 13. Pesquisa de 25 alunos do turno matutino

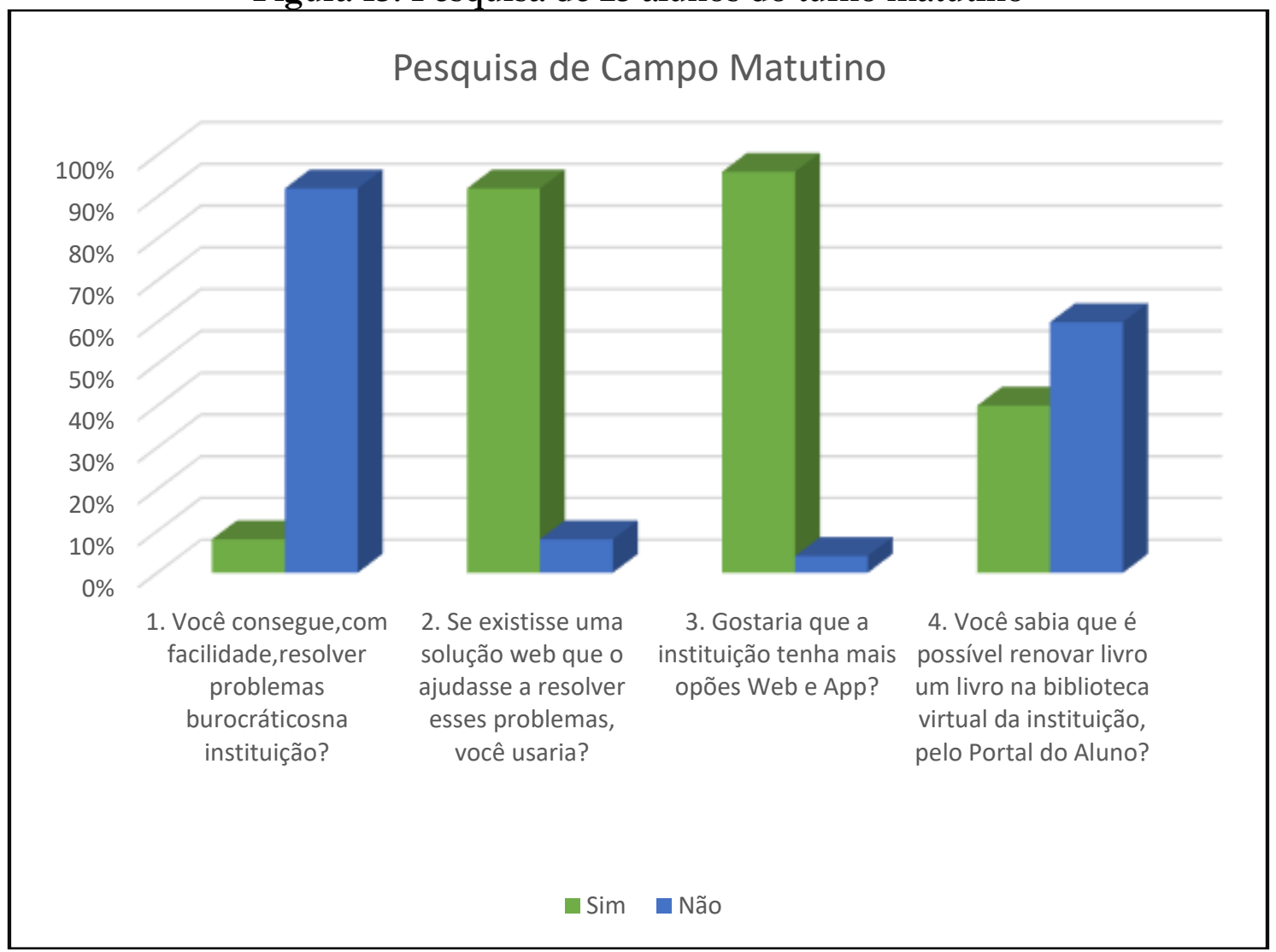

Fonte: Autoria própria.

Como pode se observar na figura 13 , foram realizadas quatro perguntas pertinentes a utilização da solução apresentada, os resultados foram:

a) Primeira pergunta: houve $8 \%$ de resposta sim e $92 \%$ resposta não, isso informa que para resolver alguma questão burocráticas acaba levando bastante tempo, em que muitas vezes pode nem existir solução para aplicar na hora.

b) Segunda pergunta: os usuários que responderam sim foram de $92 \%$ e como resposta não foram $8 \%$, de acordo com o resultado existe possibilidade de os alunos usarem para solução cotidiana que possa ocorrer no momento de economizar tempo perdido. 
c) Terceira pergunta: verificou-se que $96 \%$ responderam que sim e $4 \%$ que não, então isso confirma que eles esperam várias aplicações feitas na instituição, como um caminho de facilidades.

d) Quarta pergunta: foi identificado que $40 \%$ conhecia sim e $60 \%$ não, os que conhecia, preferiam renovar o livro pela biblioteca do aluno, pois achando mais seguro e confortável renovar de forma presencial.

Figura 14. Pesquisa de 25 alunos do turno noturno

\section{Pesquisa de Campo Noturno}

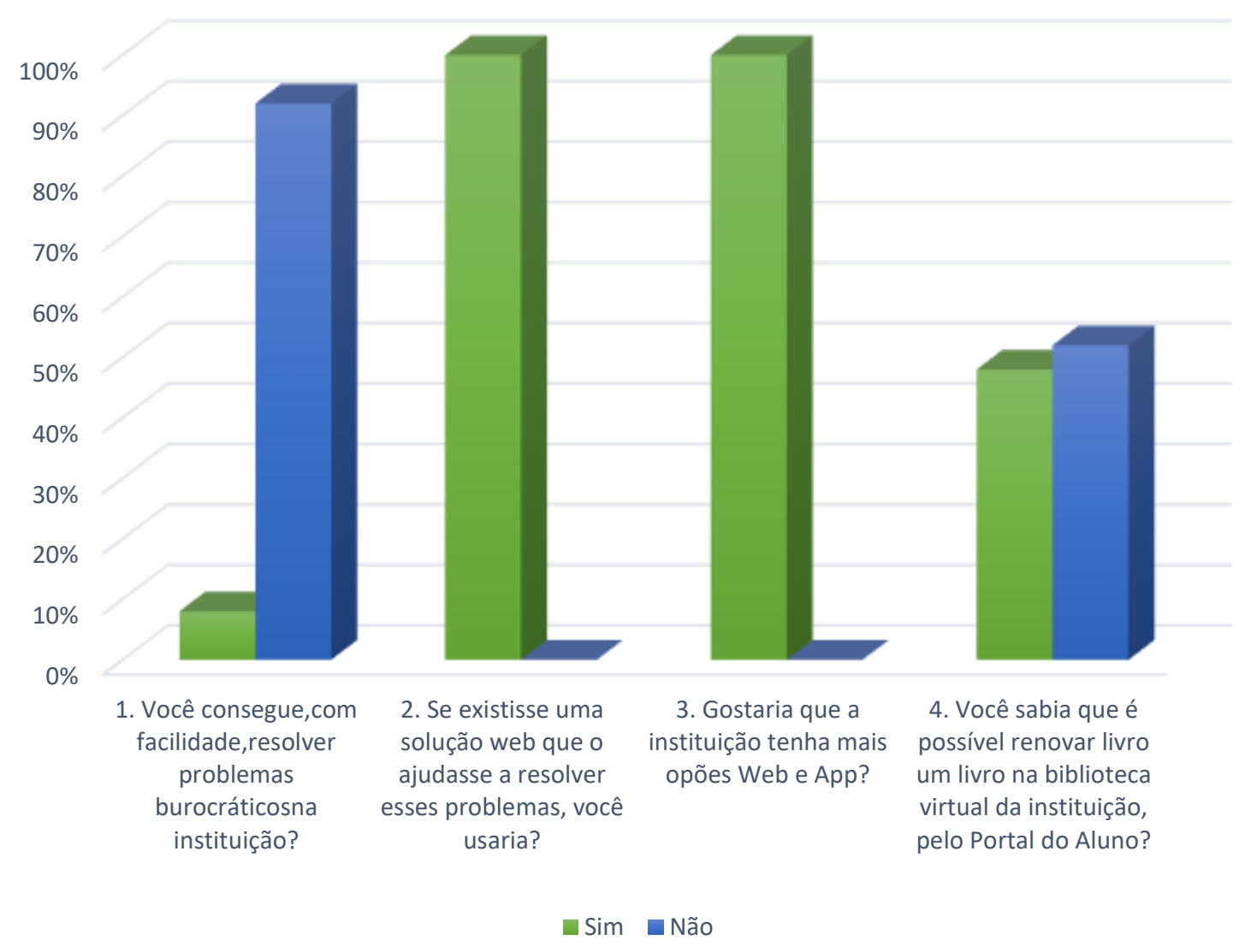

Fonte: Autoria própria.

No turno noturno, na figura 14 observou-se que:

a) Primeira pergunta: houve $8 \%$ de resposta sim e $92 \%$ repostas não, mesma situação do turno matutino, demostrando que necessita uma forma de facilidade.

b) Segunda pergunta: percebeu-se que 100\% dos usuários informaram que usariam uma solução $W e b$, como a maioria dos universitários chegam do trabalho, essa possibilidade é necessária para os auxiliarem depois de um dia cansativo.

c) Terceira pergunta: neste quesito, a quantidade de usuários que responderam que usariam uma opção Web e app (sistema $W e b$ ) também foi de 100\%

d) Quarta pergunta: neste quesito, as respostas foram bem equilibradas e diferente do resultado matutino, verificou-se que $48 \%$ pessoas conheciam a função de renovação sem precisar visitar a biblioteca física e $52 \%$ não conheciam essa possiblidade. Isso mostra que, para ter algum conhecimento de funcionalidade, é necessário que o sistema seja divulgado para que todos eles possam conhecer e utilizar. 


\section{CONSIDERAÇÕES FINAIS}

Conforme foi abordado no capítulo anterior, a grande maioria dos usuários aprovou o sistema proposta, mostrando que ele é eficiente e de fácil utilização. Porém, percebeu-se que é necessária uma maior divulgação do sistema, visto que quase $50 \%$ dos usuários não sabia da existência da solução proposta na instituição, nem das facilidades que ela poderia gerar.

Desta maneira, pode-se observar que que, através dos resultados alcançados na instituição de ensino, a solução proposta trará muitos benefícios, possibilitando um crescimento prático para solução de problemas que pode acontecer. O sistema $W$ eb é um suporte que ainda pode ter funções adicionadas, de acordo com os comentários ou e-mails enviados pelos usuários sobre o que pode melhorar.

Um aplicativo móvel com acesso ao servidor $W e b$, mostra-se uma tecnologia bastante promissora, que tende a melhorar a vida das pessoas, otimizando o acesso às informações da instituição, diminuindo a burocracia e tornando os serviços acadêmicos mais ágeis e eficientes.

Para trabalhos futuros serão feitas várias atualizações, como por exemplo, mural de semestre, avisos sobre vagas de estágios, e cursos EAD (Ensino a distância) gratuito. Esse estudo realizado, pode evitar problemas em todo corpo de colaboradores na instituição, proporcionando sempre um bom ambiente de estudo, além de prevenir atrasos de horários e entre outros.

\section{REFERÊNCIAS}

António, Paulo Francisco; Gouveia, Luis Borges. (2014). Estudo Preliminar de um Sistema de Acolhimento para Alunos da Universidade Católica de Angola. Tecnologia, Redes e Sociedade. Volume 2. Portugal (Pp. 1-35).

Costa, Carlos. Melo, C. Ana. Fernandes, Aníbal Gomes, M. Luís e Guerra, Hélia. (2010). Integração de Sistemas de Informação Universitários via Web Services, Actas da $\mathbf{5}^{\mathbf{a}}$ Conferência Ibérica de Sistemas e Tecnologias da Informação. Espanha (Pp. 290295).

Da Silva, Marco Aurélio Pereira; Neto, Newton Macedo; da Silva, Willian Ricardo Pereira. (2011), Sistema Web de Gerenciamento Acadêmico da Escola de Música Cover's, Monografia. Tecnólogo em Análise e Desenvolvimento de Sistemas. Universidade Tecnológica Federal do Paraná, Brasil.

Date, Christopher J. (2004), Introdução a Sistemas de Bancos de Dados, (oitava edição), Editora Campus, Brasil.

Freire Júnior, José Celso; Senne, Edson Luiz França; de Sena, Galeno José e dos Santos, Alessandro Waldair (2005). Sistema Web de Avaliação e Acompanhamento Acadêmico.

XXXIII Congresso Brasileiro de Ensino de Engenharia, Brasil (Pp. 2113-2127).

Garcia, Cristiano M. e Abilio, Ramon (2017). Integração entre Sistemas utilizando Web Services REST e SOAP: Um Relato Prático. Revista de Sistemas de Informação da FSMA, n. 19, Brasil (Pp. 34-41).

Kurose, Jim F.; Ross, Keith W. (2010). Redes de Computadores e a Internet: Uma Abordagem Top-Down. (quinta edição). Editora Pearson, Brasil.

Lakatos, Eva Maria; Marconi, Marina de Andrade. (2003) Fundamentos De Metodologia

Científica. (quinta edição). Editora São Paulo: Atlas, Brasil.

Larman, Craig. (2002). Utilizando UML e padrões. Editora Bookman, Brasil.

Niederauer, Juliano (2005) Integrando PHP 5 com MySQL. Editora Novatec, Brasil.

Niederauer, Juliano (2011). Desenvolvendo Websites com PHP: Aprenda a criar Websites dinâmicos e interativos com PHP e bancos de dados. (segunda edição), Editora Novatec, Brasil

Ribeiro, Admilson de Ribamar Lima; Chella, Marco Túlio; Santos, Luiz Marcus Monteiro de Almeida.; Santos, Joanna Cecilia da Silva. e Melo, Wedla Rocha (2011). LEW: Laboratório 
de Engenharia $W e b$ para ensino, pesquisa e extensão. II ENINED - Encontro Nacional de Informática e Educação Volume 2.Brasil (Pp 359-368).

Semprebom, Tiago; de Oliveira, Rômulo; Montez, Carlos (2006). Classes de Serviço em Servidores Web Apache Através de Escalonamento Adaptativo e Controle de Admissão. XII Webmedia - Simpósio Brasileiro de Sistemas Multimídia e Web, Brasil, (Pp. 273282).

Spurlock, Jake. (2013). Bootstrap. (primeira edição) Editora O’Reilly, Estados Unidos da América. Winckler, Marco Antonio; Pimenta, Marcelo Soares (2002). Avaliação de Usabilidade de Sites Web. Escola de Informática da SBC Sul, v. 1, Brasil (Pp. 85-137). 